\title{
El cargo de Ästhetizismus en la impugnación de Leo Strauss a El Mito del Estado de Ernst Cassirer
}

\author{
(4) Pablo Dreizik \\ Universidad de Buenos Aires, Argentina
}

Recibido el 24/3/2018; aceptado el 20/5/2018.

\begin{abstract}
Resumen
A partir de la publicación de "Zur Auseinandersetzung mit der europäischen Wissenschaft" en 1924, Leo Strauss inaugura una línea crítica, que se prolongara hasta 1956, dirigida a poner en cuestión aspectos fundamentales del pensamiento de Ernst Cassirer. En el curso de esta línea crítica -en su reseña al libro El mito del Estado publicada originalmente en Social Research en 1947-, Leo Strauss levanta contra Ernst Cassirer el cargo de Ästhetizismus -'esteticismo'-. En este trabajo propongo una revaluación del cargo dirigido por Leo Strauss al conjunto de la obra filosófica de Ernst Cassirer.
\end{abstract}

The charge of Ästhetizismus in the contestation of Leo Strauss to The Myth of the State of Ernst Cassirer

\begin{abstract}
From the publication of "Zur Auseinandersetzung mit der europäischen Wissenschaft" in 1924, Leo Strauss inaugurated a critical line, which lasted until 1956, aimed at questioning fundamental aspects of the thought of Ernst Cassirer. In the course of this critical line -in his review of the book The Myth of the State published originally in Social Research in 1947-, Leo Strauss raises against Ernst Cassirer the charge of Ästhetizismus -'aestheticism'-. In this paper I propose a reevaluation of the charge of aestheticism directed by Leo Strauss to the whole of the philosophical work of Ernst Cassirer.
\end{abstract}

En su reseña "Review of Ernst Cassirer's The Myth of the State" de 1947 publicada en Social Research, Leo Strauss dirige una impugnación categórica al argumento central de El mito del Estado de Ernst Cassirer (Strauss 1959: 292-296). La impugnación concierne a la debilidad -por carencia de un criterio normativo- del texto de Cassirer para realizar un análisis cierto de las tradiciones intelectuales que habrían habilitado la posibilidad del surgimiento de movimientos totalitarios -el fascismo y el nacional socialismo- en Europa durante la década del treinta. En su reseña Strauss precisa el
Palabras clave

Cassirer Strauss Esteticismo Filosofía Política

Keywords

Cassirer Strauss Aestheticism Political Philosophy 
1. Acerca de las tempranas reticencias de Leo Strauus respecto de Cassirer, HansGeorg Gadamer en 1981 recordaba: “He [Leo Strauss] had studied under Cassirer at Hamburg but had little sympathy for his political views" (Gadamer, 1984:2).

2. La coordinación de estas formas simbólicas se encuentra relacionada con el concepto de "unidad de la cultura" [Einheitskultur] que como indica Thomas Meyer es en Cassirer una "unidad funcional" más compleja que la unidad del "sistema de la filosofía" en Hermann Cohen. Ver Meyer (2013).

3. La ausencia de una dimensión ética en la filosofía de las formas simbólicas de Cassirer fue también objeto de una aguda crítica en los años de la posguerra por parte de David Baumgardt: "Professor Cassirer has not so far outlined a positive theory of morals" (Baumgardt. 1949: 598). cargo principal que dirige al texto de Cassirer: el 'esteticismo' [aestheticism] (Strauss 1959: 295-296). Mas específicamente, para Strauss el punto ciego de los análisis de Cassirer correspondería al uso de la categoría de 'forma simbólica' -formulada y desarrollada por Cassirer a lo largo de los tres volúmenes de su Filosofía de las formas simbólicas-, la cual habría debilitado la fuerza crítica de los argumentos principales de El mito del Estado.

En lo que sigue me propongo una evaluación del cargo de esteticismo que Strauss dirige a Cassirer destacando en él el peso que para ambos filósofos mantiene -aunque en un sentido opuesto- la tradición de la Bildung; finalmente concluyo que contrariamente a las intenciones polémicas de Strauss, el sesgo estético del concepto de 'forma simbólica' en la obra filosófica de Cassirer involucra desde el comienzo una dimensión normativa.

\section{Las cuatro críticas}

La línea de impugnación de Strauss hacia algunos aspectos decisivos de la obra filosófica de Cassirer comienza en 1924 y se prolongará, a través de cuatro intervenciones, hasta 1956. En un sentido más amplio, la tesis que Strauss dedicó a la filosofía de Friedrich Heinrich Jacobi -Das Erkentnisproblem in der philosophischen Lehre Fr. H. Jacobis- de 1921 y que dirigió el propio Cassirer, ya indicaba, por la elección del tema y por la perspectiva adoptada, un claro distanciamiento de su director ${ }^{1}$ (Strauss 1997 237-292).

La más temprana de las cuatro críticas, "Zur Auseinandersetzung mit der europäischen Wissenschaft" de 1924 (Strauss 1997:341-350), se ocupa de denunciar el modo en que Cassirer habría neutralizado las instancias ética y religiosa -aquellas que para Strauss responden solamente a la pregunta por los fines y las cuestiones últimas [das Wozu]. Según Strauss, esta neutralización se haría evidente en la presentación de Cassirer de la cultura como un movimiento reglado por un ritmo de "relevamientos" [Überwindung o Aufhebung] en el que cada forma de expresión -el mito, el lenguaje y el arte- se sigue una a la otra en un movimiento de relevos o pasajes que tiene lugar de modo progresivo. ${ }^{2}$ Como ejemplo de esta forma de neutralización Strauss menciona la cuestión del "mito". Strauss indica que dentro del sistema de relevos que presenta Cassirer el momento del 'mito' representa una estructura mental objetiva legítima pues se trata de una 'forma simbólica'- de organización de los hechos [Gegebenheiten] cuyo 'relevamiento' habilitaría otras formas simbólicas más complejas de organización de los hechos -el lenguaje, el arte y la ciencia. Esta presentación, afirma Strauss, se orienta en un sentido contrario a la perspectiva de Herman Cohen para quien la trascendencia ética no sólo no podía ser derivada del mito, sino que exigía su 'eliminación' [Beseitigung] (Strauss 1997: 348).

Las conferencias “Kurt Riezler (1882-1955)" de 1955 (Strauss: 1959: 233-260) y “An introduction to Heideggerian Existencialism" de 1956 (Strauss 1988: 27-46) convergen en la misma línea de impugnación precedente pero toman como motivo principal el debate filosófico público entre Cassirer y Heidegger en Davos. Al evaluar el debate de Davos, Strauss observa que los escasos recursos argumentativos que Cassirer exhibió frente a Heidegger -su "desorientación y vacuidad" [lostness and emptiness]- (Strauss 1988: 28) mantenían directa relación con el cognitivismo de su "filosofía de las formas simbólicas" y con su recepción fallida de la herencia filosófica de Hermann Cohen a la que había neutralizado y expurgado de sus contenidos éticos (Strauss 1988: 28). ${ }^{3}$

Con la reseña de 1947, "Review of Ernst Cassirer's The Myth of the State", Strauss, sin embargo, agrega una nueva línea argumental: el cargo de 'esteticismo' 
[Ästhetizismus]. Quince años antes de esta reseña, Strauss ya había apelado al cargo de esteticismo para poner en cuestión algunas de las tesis fundamentales de $E l$ concepto de lo político de Carl Schmitt (Strauss 2010: 157), ${ }^{4}$ quien a su vez había dirigido este mismo cargo contra el liberalismo ${ }^{5}$ (Schmitt 2000). En este sentido, el término 'esteticismo' durante los debates culturales de la República de Weimar se había convertido en una imputación tan frecuentada como pasible de adquirir sentidos radicalmente disímiles (Jay, 1992); (Chytry, 1989); (Buck-Morss, 1992). ${ }^{6}$ En el caso de la crítica de Strauss a Cassirer, su demanda incluía un conjunto más amplio de críticas: la dependencia de Cassirer de la herencia Ilustrada, su adopción de la teoría de los derechos del hombre del siglo XVIII y, sobre todo, su 'traición' a la dimensión ética del sistema idealista crítico de Herman Cohen. Según Strauss el problema fundamental del "esteticismo" en que habría incurrido Cassirer consistía en que debilitaba sus propias intenciones en The Myth of State dirigidas a confrontar con el nihilismo alemán en el campo intelectual. En su reseña Strauss presenta el problema bajo la forma de una pregunta retórica:

Cassirer parece rastrear la revuelta romántica contra la Ilustración en el esteticismo. Pero ¿no es el esteticismo la esencia de su propia doctrina? [Cassirer seems to trace the romantic revolt against the enlightenment to aestheticism. But is not aestheticism the essence of his own doctrine?] (Strauss 1988: 295-296).

Dicho de otra forma, si como afirma Cassirer, la matriz de los mitos políticos modernos es imputable a la reacción romántica -cuya nota distintiva es su 'esteticismo'entonces una hipótesis como la del propio Cassirer que descansa sobre una categoría de proveniencia estética -el 'símbolo'- resulta especulativamente contradictoria y prácticamente inoperante. ${ }^{7}$

Para Strauss, en cambio, una efectiva contestación al 'mito del Estado' nihilista y totalitario hubiera exigido "una radical transformación de la filosofía de las formas simbólicas en una enseñanza cuyo centro es la filosofía moral, esto es, algo como un retorno a Hermann Cohen, el maestro de Cassirer, o incluso a Kant mismo" (Strauss 1988: 295).

\section{Auto-formación, Bildung y esteticismo}

Como hemos visto Strauss descubre en el 'esteticismo' la premisa principal y no asumida -el "soul of his own doctrine"- de Elmito del Estado. Al mismo tiempo Strauss afirma que la asunción de la premisa esteticista invalida los propósitos perseguidos por el propio texto. Mi hipótesis de lectura es que la impugnación de Strauss al argumento principal de El mito del Estado no se apoya en la comprensión del esteticismo como decadentismo, l'art pour l'art (Cassirer 1979: 200) o indiferencia hacia la esfera política; sino en su significación como Bildung, es decir, en el ideal de auto-formación, o cultivo de sí, orientado al perfeccionamiento individual que dominó la cultura alemana a partir del siglo XVIII (Koselleck, 2006; Beiser 1998: 284-99).

La figura de la Bildung, ampliamente extendida en el vocabulario estético, filosófico y político del siglo XVIII, no sólo designó un ethos orientado a la educación o a la formación del carácter individual, sino que cubrió la más amplia noción de proceso "auto-formativo de la humanidad" [Bildung des Menschen]. Así, desde esta perspectiva, aquello que se intentaba destacar era la actividad auto-constructiva o autotélica de la propia humanidad [Humanität] (Biemann 2009), un movimiento emancipador que Johann Gottfried von Herder expondría en sus Ideas para una filosofía de la historia afirmando que "el fin de la naturaleza humana es la humanidad, y para permitir a los hombres alcanzar su fin, Dios ha puesto en sus manos su propio destino" (Herder 1959: 490). En este sentido, Cassirer llegó a otorgarle tal importancia al principio
4. En su línea de impugnación, Strauss indicaba una inconsistencia en el argumento central de Schmitt en la simultánea crítica al "esteticismo" y el modo en que caía víctima de él. Para ello Strauss se detenía en el uso del término "entretenido" (Unterhaltung) e "interesante" predicados por Schmitt críticamente de la "cultura y la civilización". Estos términos, observa Strauss, pertenecen también a un universo de sentido estético. Schmitt tomó seriamente la observación de Strauss y en su contestación sustituyó el término Unterhaltung por el de Spiel como opuesto a "seriedad" (Ernst). En este sentido, Karl Löwith usufructuó polémicamente de este punto afirmando que, a su pesar, el antiesteticismo declarado de Schmitt estaba muy cerca de los románticos al negar-a partir de su decisionismo todo "acatamiento a las normas" ( Löwith, 2006).

5. Schmitt establece una analogía entre la indiferencia de la producción tecnológica por su material y la indiferencia de la estética por la ética y la política (Schmitt, 2000:18).

6. En el caso particular de Leo Strauss, él hace corresponder el esteticismo en la historia del pensamiento político con el liberalismo moderno: "la volonté générale y la estética han llegado al mundo casi al mismo tiempo" ("die volonté générale und die Ästhetik ungefährgleichzeitig in die Welt gekommen sind") (Leo Strauss, 2001: 183).

7. El mismo reproche de debilidad parece haber sido formulado por el historiado del arte y sobresaliente miembro del círculo de Aby Warburg, Edgar Wind, en su disertación profesoral de 1934 Das Experiment und die Metaphysik. Zur Auflösung der kosmologischen Antinomien En realidad, la disertación de Wind se dirigía contra la pasividad y timidez de la escuela "idealista" en general. Aun así, Horst Bredekamp sugiere que el blanco de la crítica fue efectivamente Ernst Cassirer (Bredekamp, Wild \& Whyte, 2014) Es interesante notar que Wind al igual que Strauss escribieron sus respectivas tesis bajo la dirección de Cassirer. 
8. Para un examen del lugar de la recepción del Renacimiento italiano entre los intelectuales alemanes emigrados del nazismo, ver Schiller (2005). "auto-formativo" de la Bildung -propio de las ciencias del espíritu- que se preocupó de distinguirlo claramente del movimiento de "transformación" [Umbildung] más restringido y propio del ámbito de las ciencias de la naturaleza. "Este proceso es el que distingue la simple transformación, tal como se opera en el campo del desarrollo orgánico, de la formación cultural de la humanidad" (Cassirer 1951: 191).

Por otra parte, el régimen de auto-formación de la humanidad no sólo involucraba en su despliegue una dimensión epistémica e histórica sino también un fuerte sesgo político que Cassirer presentaba como el movimiento de la "progresiva auto-liberación de la humanidad" (Cassirer, 2009a: 333).

El fondo histórico sobre el cual tuvo lugar la firme asunción de Cassirer del legado de la Bildung estuvo constituido por el amplio entusiasmo que ésta suscitó en el mundo cultural de los judíos alemanes a principios del siglo veinte. El entusiasmo de los judíos alemanes por el legado de la Bildung se explica en gran medida por su función como instrumento de integración a la sociedad alemana, a través de los espacios sociales, políticos y culturales que ella a su vez habilitaba. De este modo la adopción de los ideales constitutivos de la Bildung por parte de los judíos de habla alemana constituyó una alternativa crucial a las formas de membrecía dominantes dependientes de criterios de raza o herencia cultural. En palabras de George Mosse, la adopción de la Bildung -educación clásica, sensibilidad estética y normas de respetabilidad- por parte de los judíos alemanes significó una suerte de "tickets de ingreso a la sociedad alemana" (Mosse 1984:2). En este marco, en su trabajo filosófico Cassirer se preocupó por subrayar las continuidades filosóficas entre las tradiciones ilustradas alemana y judía. En esta dirección hay que entender la empresa de restitución emprendida por Cassirer del legado ilustrado de Moses Mendelssohn -en sus escritos "Die Idee der Religion bei Lessing und Mendelssohn" (1929) y en "Die Philosophie Moses Mendelssohn (1929)" (Cassirer 2004)- no solo como discípulo racionalista y pre-crítico de Leibniz y Wolff sino como representante del ideal cosmopolita, cívico y educativo de la Bildung [Bildungsideal] y como figura pública comprometida en la defensa de los derechos ciudadanos de la población judía.

Aun así, la generalización de la categoría de Bildungsbürgertum aplicada al conjunto de los intelectuales judeo-alemanes ha sido puesta en cuestión. En este sentido Steven E. Aschheim señaló la poco hasta ahora considerada relevancia que en el universo cultural de los pensadores judíos de habla alemana se prestó a lo que él denominó el conjunto de los "judíos más allá del liberalismo y la Bildung" (Aschheim 1996: 31). Es precisamente a partir de esta última categoría que, según Eugene Sheppard, el recorrido intelectual de Leo Strauss debería ser en realidad comprendido (Sheppard 2006: 84). De tal modo, es sobre el fondo histórico y cultural de la adopción de la tradición de la Bildung judeo-alemana en un caso, o de su rechazo en otro, que las figuras de Ernst Cassirer y Leo Strauss se recortan y se muestran disímiles entre sí.

En su interés por el carácter auto-formativo [Selbstbildung] del movimiento que organiza la construcción simbólica de la realidad, Cassirer remontó su búsqueda a formulaciones históricamente anteriores a la noción de Bildung. Así, en 1942 publica tres estudios sobre la obra filosófica de Pico della Mirandola ${ }^{8}$ en Journal of the History of Ideas (Cassirer, E. 1942) en los que destaca especialmente las postulaciones radicales del filósofo renacentista acerca de los poderes de auto-modelado [power of self-moulding] (Cassirer: 1942) de que disponen los hombres. Efectivamente, la apologética de la criatura humana como tema principal que ensaya aquí Pico tiene su punto culminante, y su más audaz apuesta, en este momento autotélico o auto-constructivo del hombre "que se forja, se construye y se transforma a sí mismo" (Mirandola 2008: 211). Sin embargo, al conceder al hombre tales infinitas posibilidades el filósofo renacentista debía, al mismo tiempo, denegarle su inscripción en una noción 
distintiva y fija de 'naturaleza humana'. De allí que el "artífice de sí mismo" aquí exaltado, sea necesariamente un ser con un grado eminente de indeterminación, una "obra de perfil indefinido" [indiscretae opus imaginis] (Mirandola 2008: 207), o aún, debido a su inherente e infinita permutabilidad, un "camaleón" [chamaleonta] (Mirandola 2008: 209). Tal visión resultaba consistente con la orientación de los desarrollos tempranos de Cassirer en "Sustancia y Función" [Substanzbegriffund Funktionsbegriff] (Cassirer 2000) dirigidos a impugnar el marco sustancialista de la explicación científica y a proponer en su lugar un marco puramente funcionalista. Y aquella perspectiva funcionalista, que en el texto de 1910 se argumentaba exclusivamente para su aplicación al campo cognitivo-científico, a fines de la década del cuarenta obtiene su versión antropológico-filosófica: "si existe alguna definición de la naturaleza del hombre, debe ser entendida como una definición funcional” (Cassirer 2009a:107-108).

Leo Strauss, en cambio, siempre mostró una marcada preocupación por la preservación de lo que él denominó "las características permanentes de la humanidad" [permanent characteristics of humanity] (Strauss 1959: 26) ${ }^{9}$ que en su opinión se encontraban en grave riesgo a causa de la emergencia del historicismo y la subsecuente pérdida de un marco normativo pre-moderno. La particular atención dispensada por Strauss al pensamiento político de Maquiavelo parece guardar, en nuestra opinión, relación con el conjunto de estas preocupaciones concernientes a la posibilidad de una amenaza siempre presente sobre los "caracteres permanentes de la humanidad". Para Strauss la nueva perspectiva habilitada por la antropología del Renacimiento al situar la naturaleza humana "en un punto arquimediano fuera de la naturaleza", promocionaba un peligroso ideal del hombre como "una materia infinitamente maleable":

\begin{abstract}
La buena sociedad en el nuevo sentido es posible siempre y cuando parta de que los hombres de cerebro suficiente puedan transformar a la mayor parte de la gente corrupta, la más corrupta materia, en incorrupta por la juiciosa aplicación de la fuerza necesaria. Puesto que el hombre no está por naturaleza ordenado hacia fines fijos, él es como si fuera infinitamente maleable (Strauss 1992:297).
\end{abstract}

Sugestivamente Strauss utiliza aquí el término "maleable", el mismo elegido por Mussolini -malleabile- para aludir a la particular relación del líder con el pueblo, a través de una clara analogía estética del modo en que el artista vuelve maleable su materia (Falasca-Zamponi 2003: 44). ${ }^{10}$

En un sentido general, el contraste en las evaluaciones de Cassirer y Strauss acerca del pensamiento filosófico y político del Renacimiento Italiano expresaba sus respectivas posiciones con relación al horizonte de la tradición liberal alemana y en un sentido más específico respecto de la experiencia histórica de una Bildungsbürgertum judeo-alemana.

\section{El alcance del momento estético del pensamiento de Ernst Cassirer}

Aunque la caracterización de Ästhetizismus es presentada por Leo Strauss como un cargo, gran parte de las lecturas contemporáneas han ponderado el término en su aplicación a la comprensión de la obra de Cassirer. Así, Birgit Recki (Recki:2007) extrae un sentido positivo del término "esteticista" [Ästhetiker] como indicación de un alcance mayor de la obra de Cassirer. Si bien es cierto que el filósofo nunca dedicó una monografía al tratamiento sistemático de los problemas estéticos, desde muy temprano esta dimensión estuvo presente. Ya durante los tempranos años en que ensenó en la Universidad de Hamburgo y frecuentó la Biblioteca Warburg, Cassirer publicaba en la prestigiosa Zeitschrift für Ästhetik und Allgemeine Kunstwissenschaft
9. Con todo, la preocupación de Leo Strauss por la preservación de las "características permanentes de la naturaleza humana" no significa en su caso sostener una tesis fuerte acerca de la existencia de una "naturaleza humana". En Natural Right and History Strauss distingue claramente la "naturaleza humana" de la "virtud humana" considerando sólo a esta última como un motivo pertinente de la filosofía: "human nature is one thing, virtue or the perfection of human nature is other" (Strauss 1965: 145).
10. La figura de la "maleabilidad" en su contexto estético-político schilleriano también encontró en el temprano sionismo su momento de recepción. En un trabajo de 1901, Martin Buber propone con carácter programático la idea schilleriana de un Estado estético, Ästhetischer Staat, a través de la metáfora de la creación escultórica pueblo "Ver en nuestra gente el material para una estatua y no te confundas porque el material no es de mármol de Paros - Carrara que resiste" [In seinen Volke das Material für reine Statue sehen, und sichen nicht dadurch verwirren Lassen, dass dieses Material nich Marmor von Carrara, sondem zähes schwerfälliges, widerstresebendes Gestein ist] (Buber 1999:107). 
-dirigida por Max Dessoir- trabajos sobre el problema cognitivo del espacio estético y sobre la teoría del símbolo en Goethe -entre ellos, sobre todo "Goethes Pandora" (1924), "Die Bedeutung des Sprachproblems für die Entstehungder neueren Philosophie" (1927 y "Mythischer, ästhetischer und theoretischer Raum" (1931) (Cassirer, 2013). Pero, sobre todo, fueron las afirmaciones sobre la matriz estética de la noción de "formas simbólicas" las que justificarían la caracterización de "esteticismo" al conjunto de la obra de Cassirer. Esta importante idea acerca de la procedencia originalmente estética de todas las "formas simbólicas" se encuentra ya presente en una conferencia publicada en 1923 como "Der Begriff der symbolischen Form im Aufbau der Geisteswissenschaften" (Cassirer, 2013: 169), brindada por Cassirer en la Biblioteca Warburg en 1922 en la que el "concepto de símbolo" [Symbolbegriff] es remitido en términos generales a la obra de Goethe, Schelling y Hegel, y en términos específicos a la obra del hegeliano Friedrich Theodor Vischer quien había adoptado la noción de 'símbolo' como fundamento de la estética. Cassirer manifestaba allí que él deseaba expandir la concepción estética de Vischer a una noción más amplia que pudiera cubrir cada forma del espíritu humano -no sólo del arte- extendiéndose hacia el lenguaje y el mundo mítico (Cassirer, 2013: 169-200).

Sin embargo, la presencia de la dimensión estética en las formas simbólicas no solo se reconoce en el nivel 'genético' de su configuración y procedencia sino sobre todo en términos de su función, es decir, de su lugar en el sistema de relevamientos -entre el mito, el lenguaje y la ciencia- que organiza el movimiento del mundo simbólico de la cultura humana. En términos de su función la instancia estética cobra relevancia crucial en su función de pasaje o ruptura del enraizamiento del hombre en el espacio vital y de subsecuente ingreso al mundo de la objetividad de las estructuras y relaciones puras [System derreiner Funktions-und Beziehungszusammenhäge] (Cassirer, 2009b: 73).

La modalidad de este pasaje adquiere un fuerte sentido normativo al ser formulado en términos de liberación. Precisamente, el argumento acerca de la naturaleza liberadora del arte en relación al ámbito del mito cierra su trabajo de 1924 "Sprache und Mythos. Ein Beitrag zum Problem der Götternamen": "La imagen sólo alcanza su función puramente representativa y específicamente estética cuando el círculo mágico, al que lo limita la conciencia mítica, es roto" (Cassirer, 2013: 212). Así, la ruptura del "círculo mágico' permite "una vida [del lenguaje] ya no sujeta a lo mítico, sino estéticamente liberada" (Cassirer, 2013: 213).

Cassirer vuelve sobre la cuestión durante el debate con Heidegger en Davos en 1929:

Si se considera que por encima de este espacio expresivo [del mito] se construye el espacio representativo del arte [über diesem Ausdrucksraum der künstlerische Dartellungsraum], y finalmente, el espacio representativo propio de la matemática y de la física, se reconoce ahí esa trascendencia singular [jeneeigentümliche Transzendenz] en la que el hombre, gracias a la energía simbolizante que le es propia, se comprende él mismo en su mundo y comprende el mundo en él (Cassirer 2009b: 72-73).

La tesis avanzada por Cassirer respecto de la capacidad que la esfera estética exhibiría para trascender o romper con la atmósfera mítica recibe un tratamiento más complejo en las páginas finales del segundo tomo de La filosofía de las formas simbólicas. Efectivamente, en las páginas dedicadas a la "dialéctica de la conciencia mítica" la capacidad asignada a la esfera estética de quebrar el pensamiento mítico cobra especial significado al ser contrastada con la opuesta incapacidad que Cassirer le atribuye a la conciencia religiosa de poder ejecutar ese mismo movimiento. Efectivamente, según Cassirer, aunque la lógica de la conciencia religiosa logra poner en crisis la forma del mito al introducir una antítesis entre la "significación" de la 
"imagen" -allí donde el mito identificaba ambas-, la conciencia religiosa y su crisis no permiten el relevo y superación de la conciencia mítica: "La conciencia religiosa se sigue caracterizando porque en ella nunca cesa el conflicto entre el puro contenido significativo que entraña, y la expresión plástica de ese mismo contenido" (Cassirer, 1972: 117).

Aunque la conciencia religiosa ha discriminado las esferas del "significado" y de la imagen", esta última se mantiene inherentemente ligada a la dimensión del significado, su legalidad depende de la pregunta por su verdad. En una dirección diferente, la imagen en la esfera estética es indiferente a la existencia de su objeto y ya no depende de la verdad de su significado. ${ }^{11}$

Dada esta prescindencia, la esfera estética es la única capaz de cumplir la salida del mito: "La conciencia estética es la primera que verdaderamente supera este problema" (Cassirer, 1972: 308). El privilegio diferencial de la condición estética de la imagen respecto de su condición religiosa reside en que en la primera su significación puramente inmanente vuelve irrelevante cualquier pregunta por la verdad de su objeto. Al confesarse ilusoria, la imagen estética "tiene su propia verdad, posee su legalidad propia" (Cassirer, 1972: 318-319) De este modo, las imágenes, al tornarse inmanentes y conscientemente ilusorias, ya no se ponen como "una cosa independiente frente al espíritu" sino que adquieren el carácter de "una pura expresión de su propia fuerza creadora" (Cassirer, 1972: 319).

Esta presentación de dos clases diferentes de "ilusión" [Illusion], cuya distinción descansa en que la primera -la religiosa- no se comprende como tal, mientras que la segunda -la artística- sí lo hace, es compartida por la obra temprana de Sigmund Freud sobre todo en "El porvenir de una ilusión" (Freud 1992a) y en trabajos precedentes sobre el arte del Renacimiento -"Un recuerdo infantil de Leonardo da Vinci"(Freud: 1992b) y “El Moisés de Miguel Ángel” (Freud: 1992c). Ambos autores, durante un período similar, depositaron su confianza en el momento del arte para, usando un término de Hans Blumenberg, "re-ocupar" el lugar del pensamiento mítico o religioso. La dinámica de esta lógica de relevos -y sobre todo su dirección teleológica- le otorgará a las narrativas de Cassirer y de Freud su cualidad secular o ilustrada. ${ }^{12}$

Pero será en su trabajo de 1931 "Espacio mítico, estético y teórico" [Mythischer, ästhetischer und theoretischer Raum] (Cassirer, 2013: 317-333) que Cassirer establezca con claridad, en el contexto de su esquema de la filosofía de la cultura, la condición de forma a priori constructiva que exhibe la estética. En este trabajo el momento estético indica un tipo particular de organización y formación del espacio que Cassirer denominará el "espacio presentativo" (Darstellungsraum) y que se distinguirá de la configuración del espacio que provee el mito -"espacio expresivo" (Ausdruckraum)- y del que provee la ciencia- "espacio significativo" (Badeutungnsraum). Para los tres tipos de espacio Cassirer reconoce una misma ley de formación: la proyección de un tipo de distanciamiento respecto de "lo inmediatamente dado" [primärvorhanden] (Cassirer, 1994: 10). ${ }^{13}$ Tal distanciamiento funciona de modo progresivo hacia niveles de cada vez mayor abstracción y complejidad simbólica, desde el espacio mítico al espacio lógico-científico. ${ }^{14} \mathrm{~A}$ su vez, el movimiento progresivo de distanciamiento significa en su despliegue la obtención de una ganancia progresiva de objetividad: "Pues como contenido de la presentación artística, el objeto [Objekt] cambia a una nueva distancia, se aleja del yo; solamente haciendo esto gana su propio ser independiente y crea una nueva forma de 'objetividad"' (Cassirer, 2013: 328). Pero, en un aspecto que nos interesa destacar, el movimiento creciente de distanciamiento y abstracción no sólo comporta una ganancia de objetividad sino que también supone una dimensión normativa en términos de adquisición de un 'nuevo grado de libertad": "En el espacio
11. Esta distinción entre mito y estética es enfatizada a partir de un criterio kantiano, "la contemplación estética es por completo indiferente a la existencia o inexistencia de su objeto, pero precisamente semejante indiferencia es por entero ajena a la imaginación mítica" Ernst Cassirer (2009a: 117).

12. Victoria Kahn desarrolla de manera sobresaliente este argumento (2014: 115-146).

13. La impugnación de Cassirer del "mito de lo dado" influyó profundamente en la crítica epistemológica de Willfrid Sellers, quien además adoptó el mismo término. Al respecto véase Sellars (1956: 253-329).

14. No se trata sin embargo de una sucesión lineal. Para un desarrollo esclarecedor de este punto ver (Hagelstein, 2010: 176-189). 
15. Las páginas finales de La filosofía de las formas simbólicas II. El pensamiento mítico exhiben el mismo argumento sobre la capacidad de la esfera estética de desligarse de la esfera mítica "Frente a la realidad empírica de las cosas, esas imágenes confiesan ser 'ilusión', pero esta ilusión tiene su propia verdad, puesto que posee su legalidad propia. Al retornar a esta legalidad surge una nueva libertad de la conciencia" (Cassirer, 1972: 318-319).

16. En el curso de su empresa filosófica Cassirer recupera la categoría de "reflexión" no sólo del texto de Friedrich Schelling sino particularmente de la crítica de Johann Gottfried von Herder a la teoría del lenguaje de la llustración como un mero instrumento pasivo aplicado para organizar un universo de objetos pre-dados. La "reflexión" tal como es rescatada por Cassirer de las formulaciones de Herder en Abhandlungüber den Ursprung der Sprache (1772), permite devolverle al lenguaje su capacidad espontánea de configurar mundos (Cassirer, 1971: 105).

17. Una perspectiva radicalmente contraria puede encontrarse en los análisis de Paul de Man, quien pone en relación la estética schilleriana con las ideologías estéticas totalitarias (de Man, 2000: 119-220). Para una discusión sobre

este punto véae Kaiser (2004: 39-58).

18. El término "liberalismo de la distancia" [Liberalismus der Distanz] es utilizado por Felix Heidenreich en relación con Hans Blumenberg quien, a su vez, había encontrado en Cassirer indicaciones fundamentales para el desarrollo de este concepto. Por otra parte, Hans Lindahl ha puesto en relación, de manera muy consistente, el proceso de distanciamiento en Cassirer con los desarrollos de filosofía política de Claude Lefort, ver Lindahl (1998).

19. Para una lectura de la inspiración política del pensamiento de Cassirer en relación a la tradición del pensamiento político de Alexander von Humboldt ver Moynahan (2009). Para una perspectiva sobre la vía alemana del pensamiento liberal en contraste con la tradición inglesa ver Krieger (1957).

20. Las ansiedades proyectadas sobre la dimensión estética en el contexto de la República de Weimar y su relación con las alternativas teológico-políticas del período son analizadas en Nirenberg (2015).

21. En esta cuestión es útil recurrir a la cuidadosa distinción que propone Anthony J. Cascardi entre "esteticismo liberal" y "liberalismo estético" (Cascardi, 1992: 302). estético, sin embargo, los sentimientos y la fantasía oscilan en un nivel diferente y, cuando se lo compara con el mundo del mito, hemos ciertamente alcanzado un nuevo grado de libertad" (Cassirer, 2013: 328). ${ }^{15}$

Por lo tanto el momento estético, debido a su alegada capacidad para quebrar la adherencia a la atmósfera o "campo de fuerzas" (Kraftfelder) (Cassirer 2013:183) del espacio mítico, implica una condición normativa al suscitar la adquisición de un nuevo grado de libertad. Tal perspectiva estética de la libertad encuentra respaldo en las elaboraciones de Kant acerca de la "libre legalidad de la imaginación" (Kant, 2005: 84 \$22) y las posteriores puntualizaciones de Schiller sobre la "libertad estética" [asthetische Freyheit] (Schiller 1999: 267-278). En relación a esta tradición convocada por Cassirer el interés principal recae sobre la noción de Schiller de "reflexión" [Reflexion $]^{16}$ como puesta a distancia del objeto con relación al mundo inmediato circundante. Cassirer cita a este respecto un fragmento de la carta vigésimo quinta de las Cartas sobre la educación estética del hombre: "Mientras que el apetito vehemente aprehende directamente su objeto, la contemplación aleja [in die Ferne] el suyo de sí y, al protegerlo de la pasión, lo convierte en su propiedad verdadera" (Schiller 1999: 333).

En el mismo párrafo Cassirer gira su atención hacia una decisiva inflexión política que Schiller le otorga a su noción de "reflexión" cuando este afirma que "La contemplación (o reflexión) es la primera relación liberal [das erste liberale Verhältnis] del hombre con el mundo que le rodea" (Schiller 1999: 333). ${ }^{17}$

En estas líneas es posible identificar no sólo la capacidad que retendría la esfera estética de romper con la atmósfera mítico-religiosa, sino también la distinción de un tipo particular de relación con el mundo que aquí recibirá la valencia política precisa de "liberal" (Curthoys 2013). Si, como aquí se afirma, la esfera estética puede propiciar una 'relación liberal' con el mundo, esta posibilidad descansa en la naturaleza de aquella de proyectar de una cierta distancia. Por tanto, a la clase de liberalismo que Cassirer propone aquí le conviene la caracterización de "liberalismo de la distancia" (Heidenreich, 2011). ${ }^{18}$ Pero es, sobre todo, la noción de "individualidad estética", que Cassirer recoge de Alexander von Humboldt, aquella que mejor permite observar la articulación del pensamiento político liberal con la esfera estética. La noción de 'individualidad estética' tuvo un desempeño crucial en los desarrollos del liberalismo político de Humboldt al otorgarle a este un sesgo distintivo respecto, sobre todo, de la tradición liberal que tuvo lugar a partir de los trabajos de Locke. Más precisamente, la apelación de Humboldt al momento estético de la individualidad significaba en palabras de Cassirer que el liberalismo, en este caso, no consistía en "el derecho a la libertad dentro de una esfera especifica individual amurallada, como en el caso de la libertad de conciencia o de la libertad de pensamiento", sino en el fundamental "derecho a la diferencia" [Eigentümlichkeit $^{19}$ (Cassirer 1994b: 329).

Como hemos intentado mostrar, el cargo de esteticismo que Leo Strauss dirigió a El mito del Estado de Cassirer parecía resumir las ansiedades que Leo Strauss proyectaba sobre el conjunto de la filosofía de las formas simbólicas: el temor al carácter auto-formativo de la personalidad en los términos del ideal de la Bildung y el temor a la historicidad de las formas simbólicas como un peligro siempre en ciernes sobre las "características permanentes de la humanidad". Ambos aspectos parecían estar cubiertos por la denominación de esteticismo. ${ }^{20} \mathrm{Sin}$ embargo, Strauss al indicar con agudeza el sesgo estético que subtendía la entera obra especulativa de Cassirer, pareció no advertir en ese mismo sesgo el carácter político que le era inherente. ${ }^{21}$ 


\section{Bibliografía}

"Aschheim, S (1996). Culture and Catastrophe: German and Jewish. Confrontations with National Socialism and Other Crises. New York: New York University Press,

" Baumgardt, D. (1949). Cassirer and the Chaos in Modern Ethics. En Arthur Schilpp (Eds). The Philosophy of Ernst Cassirer. Illinois: The Library of living philosophers $(\mathrm{VI})$.

» Beiser, F. (1998). A Romantic Education: The Concept of Bildung in Early German Romanticism. En Amelie Rorty (Ed.). Philosophers on Education (pp. 284-99). Londres: Routledge.

» Biemann, A. (2009). Inventing New Beginnings: On the Idea of Renaissance in Modern Judaism. California: Stanford University Press.

» Bredekamp, H, Wild, J \& Whyte I-B (2014). False Ski-Turns: Edgard Wind's Critique of Heidegger and Sartre. Art in Translation, 6 (2) 215-236.

» Buber, M. (1999). The First Buber: Youthful Zionist Writings of Martin Buber. New York: Syracuse University Press.

» Buck-Morss, S. (1992). Aesthetics and Anaesthetics: Walter Benjamin's Artwork. Essay Reconsidered. October, 62, 3-41

" Cascardi, A. (1992). The Subjects of Modernity. Cambridge: University Press

» Cassirer, E. (2009 a). Antropología filosófica (Trad Eugenio Imaz). México: Fondo de Cultura Económica.

»Cassirer, E (1971). Filosofía de las formas simbólicas I. México: Fondo de Cultura Económica.

"Cassirer, E (1972). Filosofía de las formas simbólicas Il El pensamiento mítico. México: Fondo de Cultura Económica.

» Cassirer, E (2009 b). El debate de David del año 1929 entre Cassirer y Heidegger. En Aramayo, R. (Introd y trad.). Cassirer y su Neo-Ilustración. Madrid: Plaza y Valdés Editores.

" Cassirer, E. (1942). Giovanni Pico della Mirandola: A Study in the History of Renaissance Ideas. Journal of the History of Ideas, 3, 123-144.

»Cassirer, E. (1951). Las ciencias de la cultura. México: Fondo de Cultura Económica.

" Cassirer, E. (1979). The educational value of art (1943). En Donald Phillip Vereene (Eds.) Ernst Cassirer Symbol, Myth, and Culture: Essays and Lectures of Ernst Cassirer, 1935-1945. New Haven and London: Yale University Press.

» Cassirer, E. (1992). Kristeller, P. O. \& Wiene, P. P. (Eds.) Renaissance Essays New York: University Rochester Press.

"Cassirer, E. (1994a). Substanzbegriff und Funktionsbegriff. Untersuchungen über die Grundfragen der Erkenntniskritik. (1910). Darmstadt: Wissenschaftliche Buchgesellschaft

" Cassirer, E. (1994b). Freiheit und Form. Studien zur deutschen Geistesgeschichte (1916) Darmstadt: Wissenschaftliche Buchgesellschaft.

" Cassirer, E. (2013). S. G. Lofts y A. Calcagno (Eds.) The Warburg Years (1919-1933) Essays on Language, Art, Myth, and Technology. New Haven and London: Yale Uni- 
versity Press.

" Chytry, J. (1989). The Aesthetic State: A Quest in Modern German Thought. Berkeley-Los Angeles: University of California Press.

" Curthoys, N. (2013). The Legacy of Liberal Judaism: Ernst Cassirer and Hannah Arendt's Hidden Conversation. New York: Berghahn Books.

» Freud, S. (1992a). El porvenir de una ilusión [1927]. En Obras completas, vol. XXI (pp. 1-55). Buenos Aires \& Madrid: Amorrortu.

» Freud, S. (1992b). Un recuerdo infantil de Leonardo da Vinci [1910] (Trad. José Luis Etcheverry). En Obras completas, vol. XI (pp. 53-127). Buenos Aires \& Madrid: Amorrortu.

»Freud, S. (1914). El Moisés de Miguel Ángel. En Obras completas, vol. XIII (pp. 217242). Buenos Aires \& Madrid: Amorrortu.

» Gadamer, H.G. (1984). Interpretation, 12(1), 3-34.

" Hagelstein, M. (2010). L'art entre mythe et raison (Warburg/Cassirer). En van Vliet, M. (Ed). Ernst Cassirer et l'art comme forme symbolique. Rennes: Press Universitaires de Rennes.

» Heidenreich, F (2011). Ein Liberalismus der Distanz. Zu den ideen politischen Aspekten der phänomenologischen Anthropologie Blumenbergs. Journal Phänomenologie, 35, 52-65.

» Herder, J. (1959). Ideas para una filosofía de la historia de la humanidad. Buenos Aires: Losada.

» Jay, M. (1992). The Aesthetic Ideology as Ideology; Or, What Does It Mean to Aestheticize Politics? Cultural Critique, 21, 41-61.

» Kant, I. (2005). Crítica del juicio. Buenos Aires: Losada

» Kahn, V. (2014). The Future of Illusion: Political Theology and Early Modern Texts. Chicago\&London: University of Chicago Press

» Kaiser, D. (2004). Romanticism, Aesthetics, and Nationalism Cambridge University Press.

» Krieger, L. (1957). German Idea of Freedom: History of a Political Tradition from the Reformation to 1871. Boston: Beacon Press

»Koselleck, R. (2006). Sobre la estructura antropológica y semántica de Bildung. En Historias de conceptos. Estudios sobre semántica y pragmática del lenguaje político y social. Madrid: Trotta

» Lindahl, H. (1998). Democracy and the Symbolic Constitution of Society. Ratio Juris: An International Journal of Jurisprudence and Philosophy of Law, 11(1), 12-37.

» Löwith, K. (2006). El decisionismo ocasional de Carl Schmitt. En Heidegger, pensador de un tiempo indigente. Buenos Aires: Fondo de Cultura Económica.

" Moynahan, G. (2009). Liberty and the "Coming-into-Being" of Natural Law: Hans Kelsen and Ernst Cassirer. En Breckman, W. Gordon, P.E., Dirk, M. (Eds.). The modernist imagination: intellectual history and critical theory: essays in honor of Martin Jay (pp. 58-59). New York.Oxford: Berghah Books.

» Meyer, T. (2013). Ernst Cassirer's Writings. Journal of the History of Ideas, 74, (3), 473-495.

» Nirenberg, D. (2015). Aesthetic Theology and its Enemies. Judaism in Christian Painting, Poetry, and Politics. Waltham: Brandeis University Press. 
» de Man, P. (2000). La ideología estética (trad. Manuel Asensi y Mabel Richart). Madrid: Altaya.

» Mirandola, Giovanni Pico della. (2008) Discurso sobre la dignidad del hombre (Trad. Silvia Magnavacca) Buenos Aires: Ediciones Winograd.

" Meier, H. (Ed.). (2010). Carl Schmitt, Leo Strauss y 'El concepto de lo político'. Buenos Aires: Katz.

» Mosse, G. (1985). Jewish Emancipation between Bildung and Respectability. En J. Reinharz y W. Schatzberg (Eds). The Jewish Response to German Culture. From the Enlightenment to the Second World War. Hanover: Univesity Press of New England.

»Recki, B. (2007). Die Fülle des Lebens. Ernst Cassirer al Ästhetiker. En J. Früchtl y M. Moog-Grünewald (Eds.). Ästhetik in metaphysic kritischen Zeiten. Hamburgo: Meiner

"Sheppard, E. (2006). Leo Strauss and the Politics of Exile: The Making of a Political Philosopher. Massachusetts: Brandeis University Press.

»Schiller, K. (2005). Paul Oskar Kristeller, Ernst Cassirer and the 'humanistic turn'. En Kettler, D. \& Basingstoke, G. L. (Eds). Exile, Science and Bildung: The Contested Legacies of German Emigre Intellectuals (125-138). New York: Palgrave Macmillan.

»Schiller, F. (1999). Kallias. Cartas sobre la educación estética del hombre (Trad. Jaime Feijóo y Jorge Seca). Barcelona: Anthropos.

»Schmitt, C. (2015). Catolicismo romano y forma política. Madrid: Editorial Tecnos.

»Sellars, W. (1956). Empiricism and the Philosophy of Mind. En H. Feigl \& M. Scriven (Eds.). The Philosophy of Science, vol. I (253-329). Minneapolis: University of Minnesota Press.

»Solé, M. ( 2016). Jacobi en los escritos de Leo Strauss: spinozismo, nihilismo e ilustración. Revista Páginas de Filosofía, XVII, 20.

" Strauss, L. (1959). What is Political Philosophy? And Other Studies. Chicago: The University Chicago Press.

» Strauss, L. (1997). En Meier, H. (Ed.). Gesammelte Schriften, Philosophie und Gesetz. Frühe Schriften (II, 237-292). Stuttgart: J. B. Metzler

»Strauss, L. (1988). The Rebirth of Classical Political Rationalism: An Introduction to the Thought of Leo Strauss. Chicago: The University Chicago Press

» Strauss, L. (1992). Thoughts on Machiavelli. Chicago: The University of Chicago Press.

»Strauss, L. (1965). Natural Right and History. University Chicago \& London: Chicago Press.

"Strauss, L. (2001). Hobbes' politische Wissenschaft und zugehörige Schriften-Briefe. En Gesammelte Schriften, vol. 3. Stuttgart: J.B. Metzler

»Yaffe, M. (Ed.). (2012). Leo Strauss on Moses Mendelssohn. Chicago: University of Chicago Press. 
